\title{
Cytogenetic and clinical characteristics of a case involving complete duplication of Xpter $\rightarrow \mathrm{Xq13}$
}

\author{
Syed M Jalal, Richard Dahl, Lisa Erickson, Donald Zimmerman, Noralane Lindor
}

Cytogenetics

Laboratory,

Mayo Clinic and

Mayo Foundation,

200 First Street SW,

Rochester, MN 55905,

USA

S M Jala

R Dahl

\section{Department of}

Reproductive

Endocrinology,

Mayo Clinic and

Mayo Foundation,

Rochester, MN, USA

L Erickson

Department of

Pediatrics, Mayo

Clinic and Mayo

Foundation,

Rochester, MN, USA

D Zimmerman

Department of

Medical Genetics,

Mayo Clinic and

Mayo Foundation,

Rochester, MN, USA

$\mathrm{N}$ Lindor

Correspondence to: Dr Jalal.

Received 5 July 1995

Revised version accepted for publication 23 October 1995

\section{Abstract}

True isochromosomes for $\mathrm{Xp}$ probably do not exist in a liveborn. We describe a rare case of complete $X p$ duplication and retention of the inactivation centre at Xq13. Cytogenetically, it is described as a nonmosaic 46,X,psu idic(X)(q13). Complete duplication of Xpter $\rightarrow X q 13$ was confirmed by banded analysis and FISH probes for $X$ centromere, Xp21, XIST locus, and whole chromosome paints for $X$ and $Y$. The abnormal $X$ was always late replicating.

Clinically, the patient was short statured, had primary amenorrhoea, and incomplete development of secondary sexual characteristics, but otherwise was phenotypically normal. There are no non-mosaic reported cases with complete duplication of $i(X p)$ confirmed by FISH or molecular techniques. Those cases with partial duplication of $\mathrm{Xp}$ and presence of the inactivation centre share the traits of amenorrhoea and poor secondary sexual development. To develop a clinical profile of duplication of Xp (in presence of Xq13) there is a need to study more cases. ( $(\mathcal{M}$ Med Genet 1996;33:237-239)

Key words: $\mathrm{i}(\mathrm{Xp})$ duplication characteristics.

Isochromosome $\mathrm{Xq}$ occurs with a frequency of 1 in 50000 and accounts for 15 to $20 \%$ of Turner syndrome patients in pure or mosaic form. ${ }^{1}$ Isochromosome Xp theoretically should occur in a comparable proportion, but this is not the case. This may be in part because of the presence of dicentric $\mathrm{i}(\mathrm{Xq})$ in relatively high proportion, shown either cytogenetically or molecularly, which would result in $\mathrm{i}(\mathrm{Xp})$ that is acentric and thus non-viable. There are a handful of non-mosaic cases reported to be $\mathrm{i}(\mathrm{Xp}) .^{2-6}$ In these cases, it is difficult to distinguish by only chromosome banding between $\mathrm{i}(\mathrm{Xp})$ and deletion of $\mathrm{Xq}$ resulting in a near metacentric chromosome. ${ }^{7}$ Therman et al propose that without an intact inactivation centre in the $q$ arm, the entire $p$ arm will remain active and that the disruption of genetic imbalance from such duplication will be severe. A 1993 paper ${ }^{8}$ describes a case of tall stature and amenorrhoea involving a rearranged $X(p t e r \rightarrow q 13:$ : p11.4 $\rightarrow$ pter) where molecular and FISH techniques confirmed the near duplication of $\mathrm{Xp}$. We present a rare case of complete $X \mathrm{p}$ arm duplication and proximal $\mathrm{Xq}$ duplication that included the XIST locus, which is known to be at Xq13. ${ }^{9}$ The clinical features of the case and cytogenetic implications are discussed.

\section{Case report}

The patient was a 21 year old Chilean college student referred for evaluation of primary amenorrhoea and short stature. She was a healthy infant of a normal pregnancy born at term to a 28 year old mother and 29 year old father. Although short stature was evident in early childhood, health and development were otherwise unremarkable.

Physical examination at the age of 21 years showed a height of $143.5 \mathrm{~cm}(<5$ th centile or
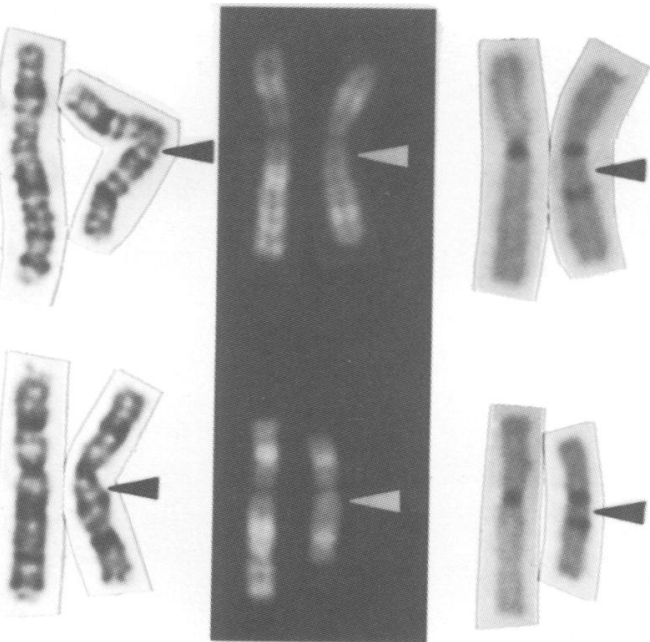

A

B

Figure 2 Normal $X$ and the psu idic(X) (q13) chromosome by GTL (A), QFQ (B), and $C B G(C)$ banding. The arrows indicate the approximate location of Figure 1 Photographs of the woman with 46,X,psu idic(X) (q13). 
50th centile for age 11.3 years), weight was $51 \mathrm{~kg}$, and head circumference was $52 \mathrm{~cm}$. The cranium was normocephalic and the facies consistent with ethnicity. The ear helices showed a prominent antihelix and normal position. The posterior hairline was not low and pterygium coli was not evident. The thyroid was moderately enlarged, symmetrical, and without nodules. The bony thorax was normal and no scoliosis was evident. Examination of the heart, lungs, and abdomen showed no abnormalities. Breast and external genitalia were consistent with Tanner III development. Internal pelvic

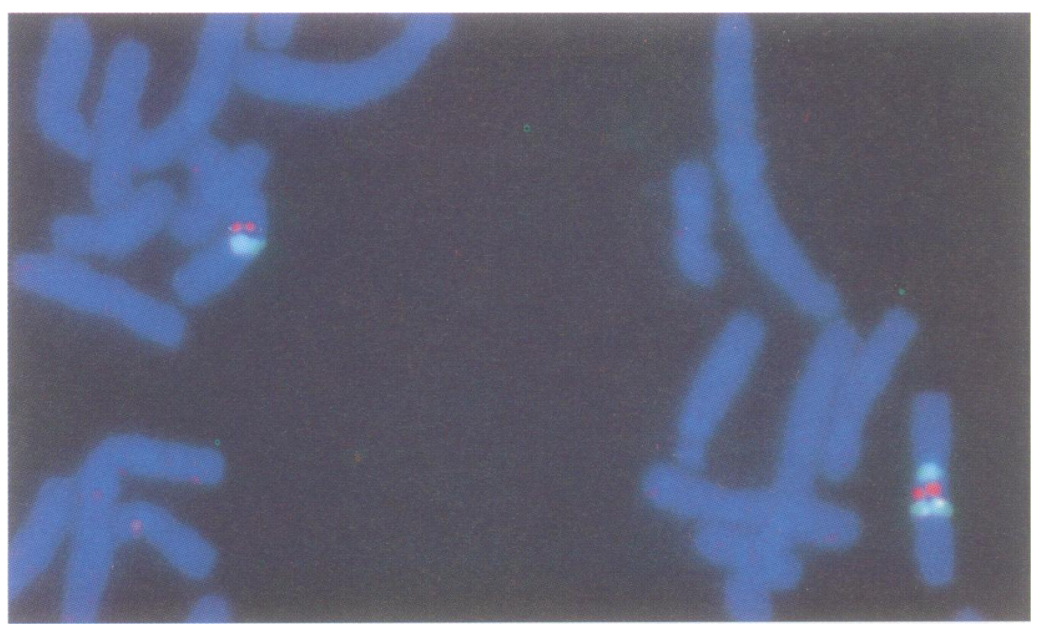

Figure 3 An alpha satellite probe specific for the $X$ centromere (green) used as a control and a cosmid probe specific for the XIST locus (orange) had XIST signal sandwiched by two centromere signals in the abnormal $X$ and single signals for the normal $X$.

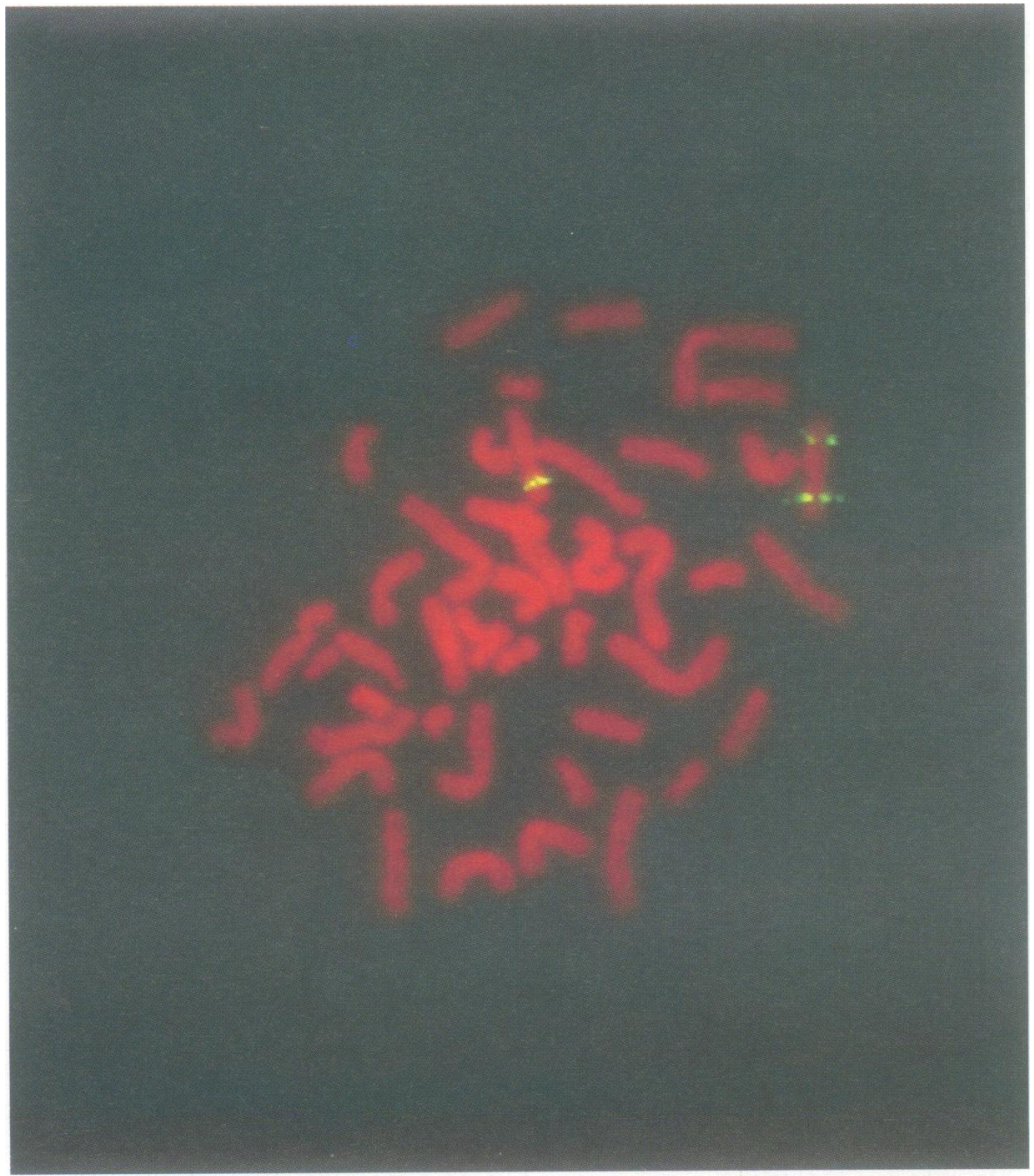

Figure $4 A$ cosmid probe for Xp21 had one signal on a normal $X$ and two on the abnormal $X$ chromosome. examination was not permitted by the patient. Morphology of the hands, palmar flexion creases, and dermal ridges were normal except for radial loops on both index fingers. The lower extremities showed mild genu valgus with patellae appearing laterally displaced and mild leg length and calf circumference discrepancy (fig 1). The neurological examination was unremarkable. A large hypopigmented macule of irregular shape was present on the forehead (it developed at the age of 14 years). The number of pigmented naevi was average.

Radiographs of the hips and knees showed mild osteopenia and open growth plates. Bone age was between 13.5 and 14 year standards. Ultrasonography of the pelvis showed a small uterus $(2 \times 4 \mathrm{~cm}$, prepubertal size), and the ovaries could not be identified. No pelvic masses were seen.

Endocrine evaluation showed a normal thyroxine level but raised sensitive TSH and thyroid microsomal antibody titre of $1: 6400$, luteinising hormone $15.5 \mathrm{IU} / 1$, and follicle stimulating hormone $44 \mathrm{IU} / \mathrm{l}$, oestradiol $20 \mathrm{pg} / \mathrm{ml}$ (normal premenopausal levels are 30-400). Chemistry testing was significant for alkaline phosphatase of $219 \mathrm{IU} / 1$ (normal 33-118), and the isoenzyme analysis showed that the rise was attributable to bone enzyme.

\section{CYTOGENETIC ANALYSIS}

Thirty metaphases from PHA stimulated blood culture were analysed by GTL, QFQ, and CBG banding techniques. Each metaphase had a pseudoisodicentric $\mathrm{X}$ with the break and fusion point at Xq13 (fig 2). The karyotype was described as $46, \mathrm{X}$,psu idic(X)(q13). Thirty consecutive analysable metaphases were scored for the replication pattern $(10 \mu \mathrm{g} / \mathrm{ml}$ BrdU, six hour terminal pulse). The psu idic $(\mathrm{X})$ (q13) was late replicating in each metaphase.

The psu $\operatorname{idic}(\mathrm{X})(\mathrm{q} 13)$ was analysed by fluorescent in situ hybridisation (FISH) using a variety of DNA probes. Modifications of the manufacturing company's protocol were similar to those described earlier. ${ }^{1011}$ Use of alpha satellite probe specific for the $\mathrm{X}$ centromere confirmed that both the active and inactive centromeres were of $\mathrm{X}$ chromosome origin. Chromosome specific paint probes for $\mathrm{X}$ and $\mathrm{Y}$ (that cross hybridise to the Xpter pseudoautosomal region) confirmed that both arms were Xp or Xp derived. The cosmid probe for the XIST locus (Vysis, Downers Grove, IL) was positive (fig 3 ) between the two centrometres, indicating the presence of the XIST gene. Oncor (Gaithersburg, MD) provided us with a probe specific for $\mathrm{Xp} 21$. Use of this probe resulted in one signal (fig 4) on each arm of the abnormal X, consistent with the banded cytogenetic interpretation of complete Xp duplication.

\section{Discussion}

Although $\mathrm{i}(\mathrm{Xq})$ reportedly occurs with a frequency of 1 in 50000 and is present in 15 to $20 \%$ of Turner syndrome patients, ${ }^{1}$ the existence of $\mathrm{i}(\mathrm{Xp})$ without the proximal $\mathrm{q}$ arm has been questioned. ${ }^{7}$ Therman et $a l^{7}$ propose that without the presence of the inactivation 
centre, which is now known to be at $\mathrm{Xq} 13,{ }^{9}$ the $\mathrm{p}$ arm duplication causes so much of a genetic imbalance that $\mathrm{i}(\mathrm{Xp})$ do not survive even as low level mosaics. Over the years their prediction seems to have held. It has been widely recognised in the last four to five years that a relatively high proportion of $\mathrm{i}(\mathrm{Xq})$ cases are demonstrably dicentric, especially by molecular techniques. Thus, if a high proportion of $\mathrm{i}(\mathrm{Xp})$ are from $\mathrm{U}$ type isochromatid fusion and acentric, they will be non-viable. This may in part explain the paucity of $\mathrm{i}(\mathrm{Xp})$.

There are some reported cases of non-mosaic $\mathrm{i}(\mathrm{Xp}),{ }^{356}$ mosaic $\mathrm{i}(\mathrm{Xp})$ with $45, \mathrm{X},{ }^{412}$ and a case of $46, X ? \mathrm{i}(\mathrm{Xp}){ }^{2}$ Whether the small near metacentric chromosome in these cases is $\mathrm{i}(\mathrm{Xp})$ or simply $\operatorname{del}(\mathrm{Xq})$, where the size of the $\mathrm{q}$ arm is about the same as the $\mathrm{Xp}$, cannot be resolved by standard banding techniques. Therman et $a l^{7}$ propose that these cases may well be Xq deletions. A range of anomalies from primary amenorrhoea, some features of Turner syndrome, endocrine hormone anomalies, to gonadal dysgenesis and essentially no other detectable dysmorphic features have been reported for these patients. Interestingly, in an extensive review, Therman and Susman ${ }^{13}$ have provided a summary of clinical features for 67 cases involving a range of deletions of the $q$ arm and 52 cases involving deletions of the $p$ arm. In their words, "one is struck by the similarity of the anomalies caused by the deletions of the two arms" as it relates to the degree of amenorrhoea, height, and other stigmata of Turner syndrome. Thus, the clinical profile may not permit a distinction between $\mathrm{q}$ arm deletion and those described for $p$ arm duplication in the earlier publications.

A recent paper by Leppig et al is directly comparable to our case. Cytogenetically, their patient is described as having $\operatorname{rec}(\mathrm{X}) \operatorname{dup} \mathrm{p}$, inv $(\mathrm{X})$ (pter $\rightarrow \mathrm{q} 13:: 11.4 \rightarrow$ pter) from a chromosomally normal mother. The short arm and XIST region of $\mathrm{q}$ arm duplication was confirmed by molecular and FISH techniques. The clinical descriptions provided for their patient are primary amenorrhoea, immature secondary sexual characteristics, tall stature with an eunuchoid habitus (90th centile), normal psychomotor development and intellect, and no features of Turner syndrome.

A case reported by Pettigrew et al ${ }^{14}$ of a 28 year old female with primary amenorrhoea and features of Turner syndrome had a very similar structural anomaly: 46,X,idic $(X)$ (pter $\rightarrow$ q13.2::q13.2 $\rightarrow$ pter). However, she had $6 \%$ 45,X mosaicism which may explain the Turner syndrome features.

An earlier case of a $17 \frac{1}{2}$ year old girl was reported by Daniel et $a l^{15}$ as a non-mosaic $\mathrm{i}(\mathrm{X})(\mathrm{pter} \rightarrow \mathrm{q} 2102 \rightarrow$ pter $)$ and had gonadal dysgenesis, short stature $(157 \mathrm{~cm})$, poorly developed secondary sexual development, but otherwise without most stigmata associated with Turner syndrome. The clinical features of this case are remarkably identical to our patient.

Our patient had some Turner-like features including short stature, hypogonadism with primary amenorrhoea, and Hashimoto's thyroiditis, but was otherwise phenotypically unremarkable. We cannot rule out the possibility of a 45,X cell line that may be tissue restricted, although there was no evidence of $45, \mathrm{X}$ mosaicism in the lymphocyte culture. Other tissue sources were not available for analysis. The difference between Leppig et $a l^{8}$ and our patient may be in part because of the lack of complete duplication of $\mathrm{Xp}$ in their case. Though the break and fusion point in the case of Daniel et $a l^{14}$ is at Xq2102 and the duplication of the Xp arm has not been confirmed by FISH or molecular techniques, the phenotype shows remarkable similarity to our patient. Duplication of the short arm with break and fusion at Xq13 or Xq2102 may well result in a similar phenotype as long as the XIST locus is present.

Cytogenetically, the present case with a karyotype of non-mosaic 46,X,psu $\operatorname{idic}(X)(q 13)$ is indeed rare with a complete duplication of $\mathrm{Xp}$ that has been confirmed by a variety of DNA fluorescent probes. The late replication study in our case confirms that the abnormal $\mathrm{X}$ is selectively inactivated. The presence of the inactivation centre (Xq13) in our case and that of Leppig et al bears out the Therman prophecy that complete expression of genes in the $\mathrm{X} \mathrm{p}$ arm in duplicate may indeed be lethal. There is a need to study more cases involving $\mathrm{Xp}$ duplication in the presence of the XIST gene, confirmed by molecular cytogenetics, to develop the associated clinical phenotypic profile.

1 Hook EB, Warburton D. The distribution of chromosomal genotype associated with Turner's syndrome: livebirth prevalence rates and evidence of diminished fetal mortality and severity in genotypes associated with structural X abseverity in genotypes associated with structural
normalities or mosaicism. Hum Genet 1983;64:24-7.

2 Caspersson C, Lindsten J, Zech L. The nature of structural $\mathrm{X}$ chromosome aberrations in Turner's syndrome as revealed by quinacrine mustard analysis. Hereditas 1970;66: 287-92.

3 de la Chapelle A, Schroder J. Isochromosome for the short arm of X, a human 46,XXpi syndrome. Ann Hum Genet 1972;36:79-87.

4 Fitzgerald PH, Donald RA. Isochromosome for the short arm of X: a human mosaic 45,X/46,XXpi, Clin Genet 1975;7: 148-54.

5 Keogh EJ, de Krester DM, Fitzgerald MG. Isochromosome for short arm of X with primary amenorrhea and pituitary tumor. Aust NZ F Med 1973;3:617-9.

6 Van den Berghe H, Fryns JP, Devos F. 46,XXip karyotype in a woman with normal stature and gonadal dysgenesis without other congenital anomalies. Humangenetik 1973; 20:163-6.

7 Therman E, Sarto GE, Patau K. Center for Barr body condensation on the proximal part of $\mathrm{Xq}$ : a hypothesis. Chromosoma (Berl) 1974;44:361-6.

8 Leppig KA, Brown CJ, Bressler SL, et al. Mapping the distal boundary of the $\mathrm{X}$-inactivation center in a rearranged $\mathrm{X}$ chromosome from a female XIST. Hum Mol Genet 1993; 7: 883-7.

9 Brown CJ, Ballabio A, Rupert JL, et al. A gene from the region of the human $\mathrm{X}$ inactivation centre is expressed exclusively from the inactive $X$ chromosome. Nature 1991;349:38-44.

10 Jalal SM, Law ME, Christensen ER, Spurbeck JL, Dewald GW. Method for sequential staining of GTL-banded metaphases with fluorescent-labeled chromosome specific paint probes. Am $\mathfrak{f}$ Med Genet 1993;46:98-103.

11 Schad CR, Kraker WA, Jalal SM, et al. Use of fluorescent in situ hybridization for marker chromosomes in congenital and neoplastic disorders. Am f Clin Pathol 1991;96:203-10.

12 Abulhasan SJ, Teebi AS, Zaki M, Hammad I, Al-Awadi SA, Abulhasan SJ, Teebi AS, Zaki M, Hammad I, Al-Awadi SA,
Krishna Murty DS. Mosaicism 45,X/46,X tdic(Xp:Xp) in

13 Therman E, Susman B. The similarity of phenotypic effects caused by $\mathrm{Xp}$ and $\mathrm{Xq}$ deletions in the human female: $\mathrm{a}$ hypothesis. Hum Genet 1990;85:175-83.

14 Pettigrew AL, McCabe ERB, Elder FFB, Ledbetter DH. Isodicentric $\mathrm{X}$ chromosome in a patient with Turner syndrome-implications for localization of the $\mathrm{X}$-inactivation center. Hum Genet 1991;87:498-502.

15 Daniel A, Saville T, Southall DB. Further dicentric X isochromosomes and deletions, and a new structure $\mathrm{i}(\mathrm{X})(\mathrm{pter} \rightarrow \mathrm{q} 2102 \rightarrow \mathrm{pter}) . \mathcal{F}$ Med Genet 1979;16:278-84. 